\title{
Transferable tetracycline resistance in Listeria monocytogenes from food in Italy
}

\author{
MANOOCHEHER POURSHABAN, ANNA MARIA FERRINI, VERUSCKA MANNONI, BRUNELLO \\ OLIVA* and PAOLO AURELI \\ Istituto Superiore di Sanità, Food Department, Viale Regina Elena, 299, 00161 Rome and *Department of \\ Experimental Medicine, Microbiology Section, University of L'Aquila, L'Aquila, Italy
}

\begin{abstract}
Mechanisms of tetracycline resistance were investigated in two recent Listeria monocytogenes isolates from food, with $L$. innocua 52P tet as a control. Tetracycline resistance was transferred conjugatively from all three strains to $L$. ivanovii and from one isolate and the control to Enterococcus faecalis. Molecular analysis demonstrated a chromosomal location for the tet determinant, which was identified as tet $M$ in all cases. These studies are the first to show that $L$. monocytogenes from food could be a source of tetracycline resistance genes able to spread to other micro-organisms.
\end{abstract}

\section{Introduction}

Listeria monocytogenes can cause severe infections in man, including septicaemia, meningitis, meningoencephalitis and abortion. Food-borne transmission is the main route of acquisition [1-5]. L. monocytogenes is generally quite susceptible to antibiotics [6] but, recently, resistant strains have been reported from foodstuffs and man [7-15]. A previous study determined the susceptibility of 148 L. monocytogenes isolates from food to antibacterial agents commonly used in human and veterinary medicine [16]. Two isolates, independently obtained from poultry and fresh meat [16], were resistant to tetracycline, flumequine, lincomycin and fosfomycin. This study examined the basis of their tetracycline resistance.

\section{Materials and methods}

\section{Bacterial strains}

Three tetracycline-resistant strains were used: the $L$. monocytogenes isolates 266 and 286 [16], which also showed resistance to fosfomycin, lincomycin and flumequine, and L. innocua 52P [13] as a control. $L$. ivanovii CIP 7842 and Enterococcus faecalis JH2-2 were used as conjugation recipients; both were already resistant to fusidic acid and rifampicin $\left(\right.$ fus $^{r} \operatorname{rif}^{r}$ ), but

Received 10 Oct. 2001; revised version accepted 7 Feb. 2002.

Corresponding author: Dr P. Aureli (e-mail: p.aureli@iss.it). were susceptible to tetracycline $\left(\right.$ tet $\left.^{\mathrm{s}}\right)$ [13]. Mutational resistance to fusidic acid (fus ${ }^{r}$ ) and rifampicin ( (if $^{r}$ ) was maintained as described below.

\section{Media and culture conditions}

Bacteria were routinely grown on Tryptic Soy Agar (TSA; Oxoid). Recipient strains were cultured in Tryptic Soy Broth (TSB; Oxoid) and TSA containing rifampicin $100 \mathrm{mg} / \mathrm{L}$ and fusidic acid $50 \mathrm{mg} / \mathrm{L}$. This double selective pressure maintained the resistance of the rif $^{\mathrm{r}}$, fus ${ }^{\mathrm{r}}$ derivatives used as recipients in conjugation experiments.

\section{Conjugation}

The mating method of Poyart-Salmeron et al. [12] was used, with some modifications. Overnight cultures of the donor strains grown in TSB containing tetracycline $5 \mathrm{mg} / \mathrm{L}$ and recipients grown in TSB with fusidic acid $50 \mathrm{mg} / \mathrm{L}$ plus rifampicin $100 \mathrm{mg} / \mathrm{L}$, were diluted 1 in 100 in TSB and mixed in a $1: 1$ ratio. A $200-\mu 1$ sample of the mating mixture was spread on a $0.45-\mu \mathrm{m}$ pore nitrocellulose membrane filter (Millipore, Molsheim, France) which was placed on TSA and incubated at $37^{\circ} \mathrm{C}$ overnight. The filter was washed and vortexmixed in TSB, which was then diluted 1000-fold and plated on TSA containing antibiotics. Transconjugants were selected on TSA with rifampicin $30 \mathrm{mg} / \mathrm{L}$, fusidic acid $20 \mathrm{mg} / \mathrm{L}$ and tetracycline $10 \mathrm{mg} / \mathrm{L}$. Transfer frequencies were expressed as the numbers of transconjugants per donor cell. 


\section{Preparation of genomic and plasmid DNA}

Genomic DNA was isolated from donor strains with Qiagen RNA/DNA Kits (Qiagen, Valencia, CA, USA); PCR amplification for tet genes was performed with the methods and primers of Aminov et al. [17]. Plasmid DNA was extracted with both Qiagen Mini and Maxi Preps, according to the manufacturer's instructions, and by the modified method of Kado and Liu [18] as described in McLauchlin et al. [19].

\section{PFGE of macrorestricted genomic DNA}

Genomic DNA for pulsed-field gel electrophoresis was prepared by the method of Moore and Datta [20], then digested overnight at $25^{\circ} \mathrm{C}$ with 20 units of SmaI (Boehringer, Germany). Electrophoresis of the resulting fragments was performed in agarose $1 \%$ gels for $20 \mathrm{~h}$ with a contour-clamped homogeneous electric field electrophoresis (CHEF) apparatus (model DRII; BioRad Laboratories, Hercules, CA, USA) at $200 \mathrm{~V}$, with a pulse time of $1-9 \mathrm{~s}$.

\section{Southern blotting and hybridisation}

SmaI-digested and undigested genomic DNA samples were electrophoresed through agarose $1 \%$ gels, then transferred to nylon membranes (Zeta-Probe, BioRad) by an alkaline transfer procedure with a vacuum blotter (Model 785, BioRad); this DNA was then hybridised under stringent conditions. The probe was the DNA fragment of the tet $M$ gene amplified by PCR from $L$. monocytogenes 266, with primers TetM-FW and TetMRV [17]. This PCR product was purified, by direct extraction from an agarose gel, with a NucleoSpin Extraction Kit (Clontech, Palo Alto, CA, USA), then labelled with alkaline phosphatase by the ECL Direct Labelling and Detection System RPN 300 (Amersham Pharmacia, Little Chalfont, Buckinghamshire).

\section{Results and discussion}

L. monocytogenes strains 266 and 286 and L. innocua 52P conjugatively transferred tetracycline resistance to L. ivanovii 7842 at frequencies of $1.9 \times 10^{-6}, 4 \times 10^{-6}$ and $6 \times 10^{-6}$, respectively. Only L. monocytogenes 286 and $L$. innocua $52 \mathrm{P}$ transferred resistance to E. faecalis $\mathrm{JH} 2-2$, with frequencies of $3 \times 10^{-7}$ and $2.4 \times 10^{-7}$, respectively. The recipient strains were all resistant to fosfomycin, flumequine and lincomycin, so it was not possible to check whether these resistance traits were also transferred. The frequencies of transfer for $L$. innocua 52P were consistent with previously reported results [13]. No plasmids were detected in the donors or the transconjugants.

Primers to detect the various classes of tet genes were used [17]. Only tet $\mathrm{M}$ was found, being present in all three strains and their transconjugants (Fig. 1). The size

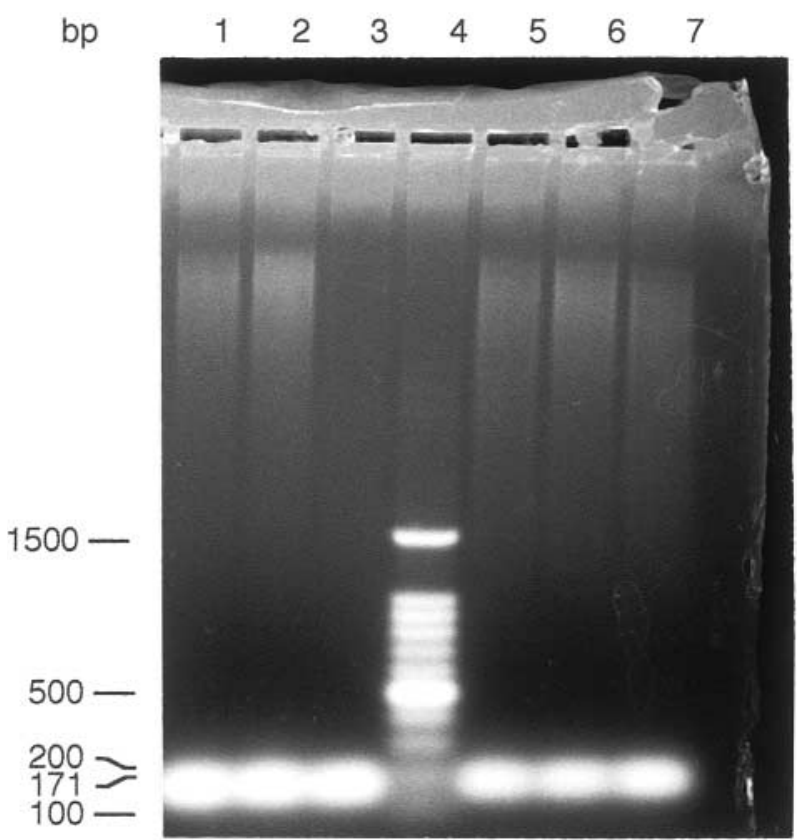

Fig. 1. Amplification of tet $\mathrm{M}$ fragments. Lane 1, L. innocua $52 \mathrm{P} ; 2$, L. monocytogenes 266; 3, L. monocytogenes $286 ; 4$, 100-bp DNA Ladder (Promega); 5, 6 and 7, L. ivanovii CIP 7842 transconjugants of strains 266,286 and 52P, respectively.

of the fragment amplified (171 bp) was consistent with that anticipated for tet $\mathrm{M}$ [17]. DNA-DNA hybridisation showed that tet $\mathrm{M}$ was located on undigested chromosomal DNA (Fig. 2); hybridisation analysis with DNA that had been digested with SmaI and separated by PFGE (Fig. 3) located the tet $\mathrm{M}$ gene on a 145-kb

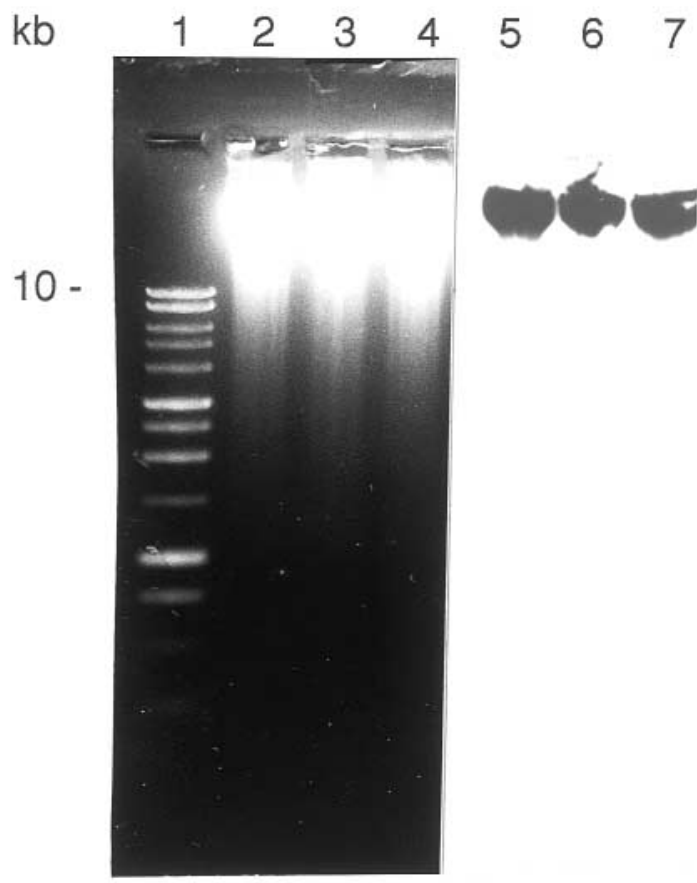

Fig. 2. Electrophoresis and hybridisation of total DNA: lane 1, 1-kb DNA ladder (Promega); 2, L. innocua 52P; 3, L. monocytogenes 266; 4, L. monocytogenes 286 . Hybridisation of the tet $\mathrm{M}$ gene probe: lane $\mathbf{5}$, L. innocua $52 \mathrm{P} ; \mathbf{6}$, L. monocytogenes 266; 7, L. monocytogenes 286. 


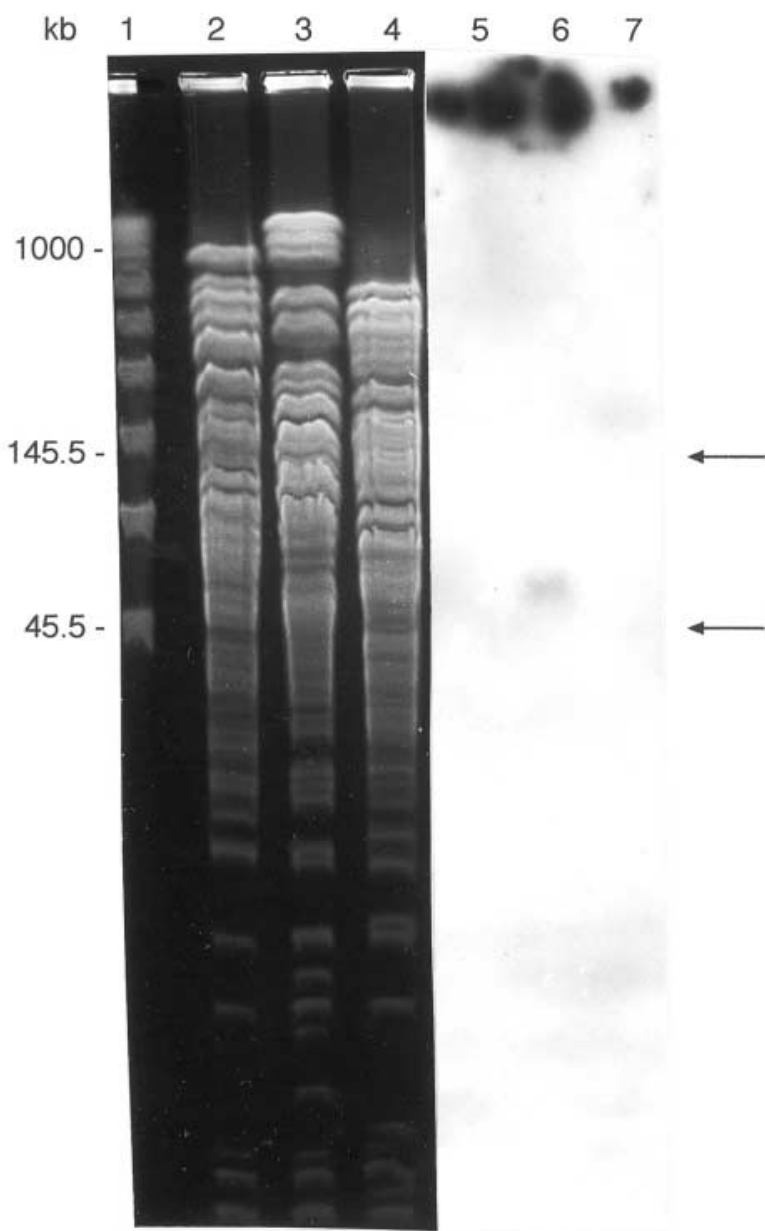

Fig. 3. SmaI digests separated by PFGE: lane 1, $\lambda$ ladder PFG Marker (New England Biolabs); 2, L. innocua 52P; 3, L. monocytogenes $266 ; 4, L$. monocytogenes 286 . Hybridisation of the blotted gel with a tet $\mathrm{M}$ gene probe: lane $5, L$. innocua 52P; 6, L. monocytogenes 266; 7, L. monocytogenes 286.

fragment in L. innocua 52P and L. monocytogenes 286 and on a $45.5-\mathrm{kb}$ fragment in digests of $L$. monocytogenes 266.

Listeria spp. are common in the environment and in the gastrointestinal tracts of animals and man. The identification of conjugatively mobile tet $\mathrm{M}$ determinants in these organisms is a cause for concern, as resistance might transfer both to and from other gut bacteria, including enterococci and streptococci [21]. The transfer of tetracycline resistance between $L$. monocytogenes and E. faecalis confirms that enterococci might act as a reservoir of genes for $L$. monocytogenes, a finding consistent with other recent data on inducible transfer of resistance in the gastrointestinal tract [13, 22-24].

We thank Professor Ian Chopra for helpful discussion and Professor B. Facinelli for providing the control strains. This work was supported by the Project 'Studio della Listeriosi alimentare ed umana e realizzazione di un sistema sperimentale di sorveglianza'.

\section{References}

1. Farber JM, Peterkin PI. Listeria monocytogenes, a food-borne pathogen. Microbiol Rev 1991; 55: 476-511.

2. Gellin BG, Broome CV. Listeriosis. JAMA 1989; 261: $1313-1320$.

3. Lorber B. Listeriosis. Clin Infect Dis 1997; 24: 1-11.

4. Rocourt J. Listeria et listeriose humaine. Ann Inst Pasteur 1990; 1: 25-30.

5. Schuchat A, Swaminathan B, Broome CV. Epidemiology of human listeriosis. Clin Microbiol Rev 1991; 4: 169-183.

6. Jones EM, MacGowan AP. Antimicrobial chemotherapy of human infection due to Listeria monocytogenes. Eur J Clin Microbiol Infect Dis 1995; 14: 165-175.

7. Biavasco FE, Giovanetti E, Miele A, Vignaroli C, Facinelli B, Varaldo PE. In vitro conjugative tranfer of VanA vancomycin resistance between Enterococci and Listeriae of different species. Eur J Clin Microbiol Infect Dis 1996; 15: 50-59.

8. Charpentier E, Gerbaud G, Courvalin P. Presence of the Listeria tetracycline resistance gene tet $(\mathrm{S})$ in Enterococcus faecalis. Antimicrob Agents Chemother 1994; 38: 2330-2335.

9. Charpentier E, Gerbaud G, Jacquet C, Rocourt J, Courvalin P. Incidence of antibiotic resistance in Listeria species. $J$ Infect Dis 1995; 172: 277-281.

10. Charpentier E, Courvalin P. Emergence of the trimethoprim resistance gene $d f r \mathrm{D}$ in Listeria monocytogenes BM4293. Antimicrob Agents Chemother 1997; 41: 1134-1136.

11. MacGowan AP, Reeves DS, McLauchlin J. Antibiotic resistance of Listeria monocytogenes. Lancet 1990; 336: 513-514.

12. Poyart-Salmeron C, Carlier C, Trieu-Cuot P, Courtieu AL, Courvalin P. Transferable plasmid-mediated antibiotic resistance in Listeria monocytogenes. Lancet 1990; 335: $1422-1426$.

13. Facinelli B, Roberts MC, Giovanetti E, Casolari C, Fabio U, Varaldo PE. Genetic basis of tetracycline resistance in foodborne isolates of Listeria innocua. Appl Environ Microbiol 1993; 59: 614-616.

14. Roberts MC, Facinelli B, Giovanetti E, Varaldo PE. Transferable erythromycin resistance in Listeria spp. isolated from food. Appl Environ Microbiol 1996; 62: 269-270.

15. Slade PJ, Collins-Thompson DL. Listeria, plasmids, antibiotic resistance, and food. Lancet 1990; 336: 1004.

16. Aureli P, Ferrini AM, Mannoni V, Hodzic S, Wedell-Weergaard C, Oliva B. Susceptibility of Listeria monocytogenes isolated from food in Italy to 17 antibacterial agents. Int $J$ Food Microbiol 2002; in press.

17. Aminov RI, Guarrigues-Jeanjean N, Mackie RI. Molecular ecology of tetracycline resistance: development and validation of primers for detection of tetracycline resistance genes encoding ribosomal protection proteins. Appl Environ Microbiol 2001; 67: 22-32.

18. Kado CI, Liu ST. Rapid procedure for detection and isolation of large and small plasmids. J Bacteriol 1981; 145: $1365-1373$.

19. McLauchlin J, Hampton MD, Shah S, Threlfall EJ, Wieneke AA, Curtis GDW. Subtyping of Listeria monocytogenes on the basis of plasmid profiles and arsenic and cadmium susceptibility. J Appl Microbiol 1997; 83: 381-388.

20. Moore MA, Datta AR. DNA fingerprinting of Listeria monocytogenes strains by pulsed-field gel electrophoresis. Food Microbiol 1994; 11: 31-38.

21. Doucet-Populaire F, Trieu-Cuot P, Dosbaa I, Andremont A, Courvalin P. Inducible transfer of conjugative transposon Tn1545 from Enterococcus faecalis to Listeria monocytogenes in the digestive tracts of gnotobiotic mice. Antimicrob Agents Chemother 1991; 35: 185-187.

22. Poyart-Salmeron C, Trieu-Cuot P, Carlier C, MacGowan A, McLauchlin J, Courvalin P. Genetic basis of tetracycline resistance in clinical isolates of Listeria monocytogenes. Antimicrob Agents Chemother 1992; 36: 463-466.

23. François B, Charles M, Courvalin P. Conjugative transfer of tet $(\mathrm{S})$ between strains of Enterococcus faecalis is associated with the exchange of large fragments of chromosomal DNA. Microbiology 1997; 143: 2145-2154.

24. Chesneau O, Lailler R, Derbise A, El Solh N. Transposition of IS1181 in the genomes of Staphylococcus and Listeria. FEMS Microbiology Lett 1999; 177: 93-100. 